\title{
O PODER DE POLÍCIA E OS DESAFIOS CONTEMPORÂNEOS NA GESTÃO DO PATRIMÔNIO CULTURAL IMATERIAL
}

\author{
POLICE POWER AND CONTEMPORARY CHALLENGES IN THE \\ MANAGEMENT OF INTANGIBLE CULTURAL HERITAGE
}

\begin{abstract}
${ }^{1}$ Walter Veloso Dutra
${ }^{2}$ Magno Federici Gomes

\section{RESUMO}

A temática objeto do presente artigo refere-se ao patrimônio cultural imaterial e a possibilidade de utilização dos instrumentos do poder de polícia sobre este. A dimensão imaterial do patrimônio cultural constitui-se dos bens portadores de referência à ação, memória e identidade das diversas culturas e grupos que formam a sociedade brasileira. A análise, por recorte metodológico, é feita a partir dos instrumentos do Inventário Nacional de Referências Culturais, o Registro e o Plano de Salvaguarda do bem imaterial, salientando que o bem intangível a ser protegido não pode ser analisado num modelo minimalista e reducionista de interpretação e aplicação da legislação existente. Por se tratar de um patrimônio vivo, o bem imaterial tem que estar protegido por um regime jurídico diferenciado, potencializado pela atuação administrativa e tendo em vista o seu caráter essencialmente dinâmico. Ao final do estudo, concluiu-se que apesar dos instrumentos que vem sendo utilizados na proteção do patrimônio imaterial (inventário, registro e plano de salvaguarda), necessário se faz a conjugação destes com a atuação do Estado e seu poder de polícia, que no cenário atual ainda se mostra tímida e ineficaz, seja pela novidade do tema ou mesmo pela ineficiência dos órgãos que detêm tal responsabilidade.
\end{abstract}

Palavras-chave: Poder de polícia, Patrimônio cultural imaterial, Instrumentos administrativos

\begin{abstract}
The object of the article refers to the intangible cultural heritage and the possibility of using the instruments of police power on this. $\mathrm{O}$ intangible cultural heritage it is composed by the action, memory and identity of different cultures and groups that form the Brazilian society. The analysis, by methodological approach, is made from the instruments of the National Cultural Inventory, registration and protection plan, noting that the intangible heritage to be protected cannot be analyzed in a minimalist and reductionist model of interpretation and application of existing legislation. Because it is a heritage "alive" must be protected by a different legal system, given its essentially dynamic character. At the end of the study, it was concluded that although the devices for the protection of intangible heritage (inventory, record and safeguard plan), the combination of these with the actions of the state and its police power is required, which in this scenario still shows shy and ineffective, given the novelty or the inefficiency of the organs that hold this responsibility.
\end{abstract}

Keywords: Police power, Intangible cultural heritage, Administrative instruments.

\footnotetext{
${ }^{1}$ Mestrando em Direito Ambiental e Desenvolvimento Sustentável pela Escola Superior Dom Helder Câmara, Minas Gerais (Brasil). Professor do Instituto Ensinar Brasil, Minas Gerais (Brasil). E-mail: w.velosodutra@gmail.com

${ }^{2}$ Doutor em Direito pelo Universidad de Deusto, Bilbao (Espanha). Professor da Pontifícia Universidade Católica de Minas Gerais - PUC/MG, Minas Gerais (Brasil). E-mail: magnofederici@gmail.com
} 


\section{INTRODUÇÃO}

Objetiva-se, com o presente trabalho, o estudo do patrimônio cultural imaterial e a forma como o poder de polícia atua sobre este. A delimitação do tema se justifica pelos questionamentos que se tem feito sobre esse novo patrimônio afeto ao Direito brasileiro, que regulamentado pela Constituição da República de 1988 (CR/1988) e delimitado pelo DecretoLei $\mathrm{n}^{\mathrm{o}} 3.551 / 2000$, ainda se vê diante de diferentes visões acerca de sua salvaguarda e a forma com que o Poder Público deve atuar na preservação deste, visto que diverge do patrimônio material e da aplicabilidade do tombamento, regulamentado pelo Decreto $n^{\circ}$ 25/1937.

O tema abordado é de suma importância por afetar diretamente o direito ao pleno exercício dos direitos culturais e acesso às fontes da cultura nacional, estatuído no art. 215, da $\mathrm{CR} / 1988$.

Trata-se de um trabalho dogmático, isto é, teórico documental, em que são analisados a teoria e os conceitos doutrinários da matéria abordada, como fonte para a formação argumentativa. O trabalho está estruturado em quatro tópicos. No primeiro, conceituar-se-á o patrimônio cultural e sua dimensão imaterial. No segundo, será examinado o poder de polícia e a polícia ambiental cultural. No terceiro tópico analisar-se-á os instrumentos de salvaguarda do Patrimônio Cultural Imaterial. E por fim, a efetividade do poder de polícia na gestão do patrimônio cultural imaterial.

\section{PATRIMÔNIO CULTURAL}

O patrimônio cultural encontra-se vinculado à ideia de memória coletiva, numa conjugação de aspectos históricos do tempo passado com as múltiplas dimensões culturais do tempo de hoje. O termo patrimônio em sentido lato pode ser entendido como quaisquer bens materiais ou morais, pertencentes a uma pessoa, instituição ou coletividade; complexo de bens, materiais ou não, direitos ações, posse e tudo o mais que pertença a uma pessoa ou empresa e que seja suscetível de apreciação econômica; herança paterna; riqueza enquanto patrimônio moral, cultural e intelectual (FERREIRA, 1999, p.1.292 ).

Reisewitz (2004, p. 88) ressalta que o patrimônio pode ser entendido como um conjunto de bens que tem valor, mas não necessariamente valor econômico. A autora (2004) sustenta que o direito vem afastando a visão predominantemente privatista e economicista do termo patrimônio, abarcando inúmeros valores que vão além das garantias individuais em relação à propriedade. 
A cultura se torna patrimônio a partir da vivência e dos processos de construção das comunidades e do Estado, que atribuem valor a determinada coisa, que se torna bem e esse bem se torna patrimônio, sendo esse objeto de proteção jurídico-estatal. Fonseca (2009, p. 35) destaca que "são essas práticas e esses atores que atribuem a determinados bens valor enquanto patrimônio, o que justificaria sua proteção".

Moreno (2003, p. 90) ao analisar a cultura enquanto patrimônio destaca que esta é:

[...] el conjunto acumulativo de bienes y de valores del espíritu creados por el hombre a través de su genuína facultad de simbolización. Por outra parte, sus concretas manifestaciones sócio-históricas, la cultura étnica, que expressa um modo de ser determinado de uma comunidad, de um pueblo o do uma nácion, portadoras de um sistema cohesionado de contenidos e valores culturales (MORENO, 2003, p. 90).

Assim, considera-se bem tudo aquilo que tem valor, e na esfera jurídica analisa-se o bem cultural como aquele bem, material ou não, significativo como produto e testemunho da tradição artística e/ou histórica, ou como manifestação dinâmica cultual de um povo ou de uma região (SILVA, 2004, p. 26).

O patrimônio cultural como bem jurídico de significativo valor encontra-se cada vez mais presente no contexto social, fazendo surgir novas relações jurídicas e novos direitos. Ao analisar esses novos direitos verifica-se o déficit na elaboração dos instrumentos jurídicos de salvaguarda dos bens culturais valorados pela sociedade, exigindo-se assim uma maior reflexão e análise a fim de se formular um aparato normativo que respalde e proteja o patrimônio cultural.

No Brasil, as discussões a respeito da salvaguarda e proteção de objetos de valor artístico e histórico começam a ter relevância a partir da década de 1920. O Movimento Modernista de 1922 inaugura o debate acerca da valorização e proteção do patrimônio cultural brasileiro propondo uma revolução artística com forte crítica aos modelos anteriores.

A partir do Movimento Modernista buscou-se uma maior atenção com a constituição da identidade nacional como patrimônio cultural, sendo este capaz de construir o valor nacional baseado no poder afetivo que o patrimônio possui para a Nação; valor cognitivo caracterizado pela importância da multiplicidade histórica, política, costume e artes que o patrimônio cultural assume, funcionando, também, como pedagogia geral do civismo e sua importância para a memória social; o valor econômico que gera políticas públicas específicas voltadas para exploração financeira que o patrimônio possui, como por exemplo, o turismo 
que proporcionam; e o valor artístico baseado na sua importância pedagógica para formação de artistas (CHOAY, 2001, p. 116-123).

Para Fonseca (2009):

\begin{abstract}
A temática do patrimônio surge, portanto, no Brasil, assentada em dois pressupostos do modernismo, enquanto expressão da modernidade: o caráter ao mesmo tempo universal e particular das autênticas expressões artísticas e a autonomia relativa da esfera cultural em relação às outras esferas da vida social. A atuação dos modernistas no SPHAN vai mostrar como eles puseram em prática, num campo cultural e político específico, e sob um regime autoritário, esses pressupostos (FONSECA, 2009, p. 92).
\end{abstract}

Em 1937 foi aprovado o Decreto-lei n ${ }^{\circ}$ 25/1937 que organizou a proteção do patrimônio histórico e artístico nacional, marcando uma nova fase para a proteção do patrimônio, ou seja, o texto inaugural de uma legislação específica sobre o patrimônio cultural no Brasil.

O Decreto-lei $n^{\circ}$ 25/1937 organizou a proteção do patrimônio histórico e artístico nacional e instituiu o tombamento como forma de proteção, mas somente estavam protegidos os bens físicos, em razão do seu excepcional valor histórico, artístico, arqueológico, etnográfico e bibliográfico ${ }^{1}$.

O conceito tradicional de patrimônio artístico e cultural vigorou por longos anos, vindo a ser modificado através da CR/1988, que diante do seu processo de redemocratização do País, deu especial tratamento ao patrimônio cultural brasileiro, alargando a concepção restrita trazida no Decreto-lei no 25/1937. A partir da CR/88 abandona-se a ideia de "fatos memoráveis da história" e partindo da noção de cultura passa-se a considerar patrimônio cultural brasileiro o bem que é portador de referência à identidade, à ação ou à memória dos grupos formadores da sociedade brasileira.

A CR/1988 representa um grande avanço na proteção do patrimônio cultural brasileiro, inaugurando uma nova concepção, mais abrangente e democrática em relação ao conceito restritivo de "patrimônio histórico e artístico nacional" definido no Decreto-Lei $\mathrm{n}^{\circ}$ 25/1937. Nas palavras de Santilli (2005):

Os novos conceitos constitucionais são frutos de um longo processo histórico de institucionalização de políticas de preservação cultural, que procuraram abandonar a perspectiva elitista, monumentalista e sacralizadora de patrimônio cultural, e

\footnotetext{
${ }^{1}$ Art. $1^{\circ}$. Constitui o patrimônio histórico e artístico nacional o conjunto dos bens móveis e imóveis existentes no país e cuja conservação seja de interesse público, que por sua vinculação a fatos memoráveis da história da Brasil, quer por seu excepcional valor arqueológico ou etnográfico, bibliográfico ou artístico (BRASIL, 1937).
} 
valorizar a cultura viva, enraizada no fazer popular e no cotidiano das sociedades (SANTILLI, 2005, p. 62).

Com o fito de abandonar o autoritarismo dos anos anteriores, a CR/1988 buscou proteger os bens dos mais diversos grupos sociais e/ou étnicos nacionais, reafirmando a pluralidade cultural brasileira. O art. 216 da CR/1988 estabelece que constituem o patrimônio cultural brasileiro os bens de natureza material e imaterial, abarcando as formas de expressão, os modos de criar, fazer e viver e as criações científicas, artísticas e tecnológicas dos diferentes grupos sociais brasileiros.

Pela nova visão trazida pela CR/1988 no momento em que um determinado bem é individualizado e reconhecido como parte do patrimônio cultural brasileiro, este passa a ser regido por um regime jurídico especial que o difere dos demais bens, isso não implica no abandono e esquecimento dos demais, mas o torna bem de interesse público e sendo relevante sua preservação (MIRANDA, 2006, p. 53).

Nesse sentido Souza Filho (2005) acrescenta:

\begin{abstract}
Pela leitura da lei e da Constituição de 1988, bem cultural é aquele bem jurídico que, além de ser objeto de direito, está protegido por ser representativo, evocativo ou identificador de uma expressão cultural relevante. Ao bem cultural assim reconhecido é agregada uma qualidade jurídica modificadora, embora a dominialidade ou propriedade não se lhe altere. Todos os bens culturais são gravados de um especial interesse público - seja ele de propriedade particular ou não. (SOUZA FILHO, 2005, p. 36).
\end{abstract}

A partir de então, o patrimônio cultural desenvolve um novo olhar na maneira de representar a nação e seu povo, liberta-se do olhar unitário que engessava as diferenças para ser analisado pela diversidade e pluralidade cultural que compõe o Brasil. Hoje fala-se em um patrimônio cultural aberto, vivo e capaz de interagir com a sociedade que o identifica e o individualiza como tal.

\title{
2.1 Patrimônio Cultural Imaterial
}

O patrimônio cultural imaterial é a possibilidade que outras manifestações da memória coletiva possam ser protegidas. A CR/1988, nos arts. 215 e 216, ampliou a noção de patrimônio cultural ao abrigar a existência de bens culturais de natureza material e imaterial, e ao reconhecer outras formas de preservação - como o Registro e o Inventário - além do Tombamento, instituído pelo Decreto-Lei n ${ }^{\circ}$ 25/1937. Assim: 
Os bens culturais de natureza imaterial dizem respeito às práticas e domínios da vida social que se manifestam em saberes, ofícios e modos de fazer; celebrações; formas de expressão cênicas, plásticas, musicais ou lúdicas; e nos lugares (como mercados, feiras e santuários que abrigam práticas culturais coletivas) (IPHAN, 2007).

A Organização das Nações Unidas para a Educação, a Ciência e a Cultura define como Patrimônio Cultural Imaterial "as práticas, representações, expressões, conhecimentos e técnicas - com os instrumentos, objetos, artefatos e lugares culturais que lhes são associados - que as comunidades, os grupos e, em alguns casos os indivíduos, reconhecem como parte integrante de seu patrimônio cultural" (UNESCO, 2003).

Perante aos anseios de atender às determinações legais e criar instrumentos adequados ao reconhecimento e à preservação desses bens imateriais, foi editado o Decreto $\mathrm{n}^{\circ}$ 3.551/2000 - que instituiu o Registro de Bens Culturais de Natureza Imaterial e criou o Programa Nacional do Patrimônio Imaterial (PNPI), consolidando o Inventário Nacional de Referências Culturais (INCR). Tais instrumentos serão analisados no tópico "Os instrumentos de salvaguarda do patrimônio cultural imaterial”.

Souza Filho (2005, p. 21) comenta acerca da importância da existência de um regime jurídico especial de proteção aos bens culturais:

\begin{abstract}
Todos os bens culturais são gravados de um especial interesse público - seja ele de propriedade particular ou não. Aliás, isto ocorre não apenas com os bens culturais, mas também com os ambientais em geral. Esta nova relação de direito entre os bens de interesse cultural ou ambiental com o Estado e os particulares vem dando margem a uma nova categoria de bens, os bens de interesse público que não se reduz apenas a uma especial vigilância, controle ou exercício do poder de polícia da administração sobre o bem, mas é algo muito mais profundo e incide diretamente na sua essência jurídica. A limitação imposta aos bens de interesse público é de qualidade diferente da limitação geral imposta pela subordinação da propriedade privada ao uso social. As limitações gerais produzem obrigações pessoais aos proprietários que devem tornar socialmente úteis as suas propriedades, enquanto as limitações impostas a esses bens de interesse público são muito mais profundas pois modifica a coisa mesma, passando o poder público a, diretamente, controlar o uso, transferência, a modificabilidade e a conservação da coisa, gerando direitos e obrigações que ultrapassam a pessoado proprietário, atingindo o corpo social, que passa a ser co-responsável, interessado e legitimado para a sua proteção, além do próprio poder público.

Ao mesmo tempo que a cidadania passa a ter direitos em relação ao bem cultural, como a visualização, a informação e o direito a exigir da Administração a sua manutenção e conservação, passa a ter obrigações em relação a ele, que estão diretamente ligados a sua proteção, constituindo crime qualquer agressão a ele cometida (SOUZA FILHO, 2005, p. 21, grifo próprio).
\end{abstract}

Assim, para que ocorra a efetiva proteção jurídica do patrimônio com dimensão imaterial é necessário à implicação de obrigações e direitos aos titulares dos bens tutelados, à 
sociedade como um todo e também ao Estado. A aplicabilidade das normas protetivas irá variar de acordo com a natureza jurídica do bem, e à realidade do contexto em que este está inserido.

Por parte do Estado, através de seu poder administrativo sancionador, na hipótese de qualquer ameaça ou dano ao horizonte imaterial e intangível dos bens imateriais protegidos, cabe no exercício do seu poder de polícia e de forma vinculada, utilizar os mecanismos administrativos e judiciais disponíveis e possíveis à busca da melhor solução ao caso concreto, inclusive a cessação do dano e sua reparação. Por se tratar de um bem de natureza intangível é necessário que tal atuação ocorra se for do interesse das comunidades, analisando-se, sempre, a situação real que lhe é posta e sempre ouvindo os interessados diretos, detentores e produtores.

Com o fito de melhor entender o papel do Estado na salvaguarda do patrimônio cultural imaterial, no tópico seguinte buscar-se-á entender o poder administrativo sancionador no exercício do poder de polícia e a sua utilização a favor do patrimônio cultural imaterial.

\section{PODER DE POLÍCIA E A POLÍCIA AMBIENTAL CULTURAL}

O poder de polícia surgiu da necessidade de ordenação do convívio coletivo e se desenvolveu não somente acompanhando a evolução dos aglomerados urbanos e cidades, mas também em função da própria expansão dos direitos individuais e sociais, cumprindo sempre o papel primordial de preservar a estrutura social dos povos e a existência do próprio Estado, segundo Meirelles (2001, p. 440).

No Brasil, a Constituição de 1824 já fazia menção a posturas municipais a serem exercidas pelas Câmaras Municipais, a Lei de 01 de janeiro de 1.828 já trazia a expressão "posturas policiais" referindo-se a estas atividades. O pioneiro na utilização da expressão poder de polícia no direito brasileiro foi Rui Barbosa, em 1915, seguido por Aurelino Leal que, em 1.918 lançou o livro Policia e Poder de Polícia, fixando a expressão no Direito pátrio, como explica Medauar (1999, p. 365).

Conceituando o poder de polícia, este deve ser entendido como a atividade da Administração Pública que, por meio de atos, impõe limites ao exercício de direitos e liberdades do particular. Tal atividade pode ainda ser entendida como uma faculdade de que dispõe a Administração de em benefício da coletividade, restringir ou condicionar o exercício daqueles direitos.

Para Mello (2006, p. 795), o poder de polícia é conceituado como a: 
atividade da Administração Pública, expressa em atos normativos ou concretos, de condicionar, com fundamento em sua supremacia geral e na forma da lei, a liberdade e a propriedade dos indivíduos, mediante ação ora fiscalizadora, ora preventiva, ora repressiva, impondo fim de conformar-lhes os comportamentos aos interesses sociais consagrados no sistema normativo (MELLO, 2006, p. 795).

Na visão de Di Pietro (2007, p. 104), o conceito adotado pelo Direito brasileiro é o de que "o poder de polícia é a atividade do Estado consistente em limitar o exercício dos direitos individuais em benefício do interesse público".

Na legislação pátria o conceito de poder de polícia é trazido pela Lei ${ }^{0}$ 5.172/1.966, denominado Código Tributário Nacional (CTN), que em seu art. 78 o define como:

[...] atividade da administração pública que, limitando ou disciplinando direito, interêsse ou liberdade, regula a prática de ato ou abstenção de fato, em razão de intêresse público concernente à segurança, à higiene, à ordem, aos costumes, à disciplina da produção e do mercado, ao exercício de atividades econômicas dependentes de concessão ou autorização do Poder Público, à tranqüilidade pública ou ao respeito à propriedade e aos direitos individuais ou coletivos (BRASIL, 1966).

Toda essa ação do Estado decorre do Poder de Polícia que lhe é outorgado, valendo-se como o instrumento que este tem para perseguir e compatibilizar os interesses públicos com os privados, buscando o bem estar social.

O poder de polícia confere ao Estado o poder/dever de restringir, limitar, frear a atuação do particular em nome do interesse público, atingindo basicamente os direitos à liberdade e à propriedade. Mas, apesar de atuar na liberdade e propriedade, enquanto instrumento do Poder Público, não atinge diretamente a pessoa do particular, mas sim os direitos e atividades da pessoa em busca do atendimento ao interesse público.

O denominado interesse público refere-se às mais diversas áreas da sociedade, como segurança, saúde, defesa do consumidor, sanitária, águas, saúde, e o meio ambiente, que abarca o meio ambiente cultural e consequentemente o patrimônio cultural material e imaterial, objeto do presente estudo.

No tocante ao Direito Ambiental, Machado (2009, p. 310) define poder de polícia ambiental como as atribuições conferidas a Administração Pública para limitar e disciplinar, ato ou omissão diverso do interesse público, evitando a degradação do meio ambiente, através da prevenção ou da reparação do dano. Entende o autor (2009) que é dessa forma, que a Administração, identificada como a guardiã, se encontra no centro do conceito de poder de polícia, procurando resguardar a relação entre o homem e o meio ambiente. 
O Direito Ambiental, somando os conceitos do Direito Administrativo, trouxe para si a incumbência de analisar o patrimônio cultural por entender que este faz parte do meio ambiente, mais precisamente o meio ambiente cultural. Assim, o poder de polícia ambiental é exercido como forma de proteção ao interesse coletivo/público de preservação de bens de valor cultural, passando estes bens a estar sob tutela especial do Estado, restringindo direitos de particulares, com fim de resguardar o interesse da coletividade (RABELO, 2009, p. 45-52). Segundo Pires (1994):

\begin{abstract}
Assim, é certo que, uma vez reconhecido o caráter social do bem, em função de seu valor cultural, o qual justifica a medida de proteção, caberá ao Estado exercer o necessário poder de polícia para a garantia daquela preservação. Daí por que o poder de polícia fundamenta a ação protetora do estado em seus desdobramentos limitativos específicos, a partir do reconhecimento formal do valor social do bem via tombamento ou outro instrumento (PIRES, 1994, p. 98).
\end{abstract}

Na esfera federal, o Instituto do Patrimônio Histórico e Artístico Nacional - IPHAN tem o dever legal e regimental conferido pelo Decreto $n^{0}$ 6.844/2009 de exercer o poder de polícia administrativa ambiental, visando à preservação do patrimônio protegido pela União.

No âmbito estadual e municipal, os demais órgãos ligados à cultura também devem exercer seu poder de polícia na proteção de seus patrimônios. O Estatuto do Instituto Estadual de Patrimônio Histórico e Artístico de Minas Gerais - IEPHA-MG atribui ao órgão esse dever:

\footnotetext{
Art. $2^{\circ} \mathrm{O}$ IEPHA-MG tem por finalidade pesquisar, proteger e promover o patrimônio cultural do Estado, nos termos do disposto na Constituição Federal e na Constituição do Estado, competindo-lhe:

VIII - fiscalizar o cumprimento da legislação de proteção do patrimônio cultural, aplicar penalidades, multas e demais sanções administrativas e promover arrecadação, cobrança, execução de créditos não tributários, ressarcimentos devidos e emolumentos decorrentes de suas atividades, exercendo o poder de polícia administrativa, nos termos da legislação vigente (MINAS GERAIS, 2011, grifo próprio).
}

O bem cultural material desde o já mencionado Decreto n ${ }^{\circ}$ 25/1937 vem sendo fiscalizado pelo Estado, que no uso do seu poder de polícia, promove os atos de fiscalização, preventiva e repressiva, com o fito de verificar se o referido bem está sendo preservado, transformado, mutilado, destruído em sua materialidade.

No campo do patrimônio imaterial, o uso do poder de polícia, a sua abordagem e os efeitos jurídicos que estes geram se diferenciam substancialmente do campo do bem material. A ação do Estado deverá ser para garantir a continuidade histórica desses bens culturais 
"vivos", com caráter inventivo e dinâmico. O problema ora analisado, pauta-se quando se pensa em preservação do patrimônio cultural imaterial, é inaplicável algumas noções próprias ao campo do material, como, por exemplo, a ação fiscalizatória sobre bens culturais. Como agirá o Estado com seu poder administrativo sancionador diante de um patrimônio cultural imaterial? Quais os limites de intervenção na busca de sua salvaguarda?

No campo do patrimônio imaterial não cabe as ações adotadas na esfera material, os bens culturais salvaguardados pelo Registro relacionam-se a modos de fazer, saberes, relações sociais e simbólicas, experiências dos grupos humanos que se constituem fundamentos de identidades sociais.

O bem intangível se transforma e se modifica constantemente, com adaptações e modificações acarretadas pela ação do tempo e pela dinâmica das relações socioculturais e econômicas. Visto que tais modificações não podem ser entendidas como contrárias a proteção do bem, na esfera imaterial busca-se muito mais do que o simples registro com fins históricos, busca-se a construção de meios para que bem imaterial prossiga referenciando o grupo social que o detém, até o momento em que este o interessa.

O poder de polícia deve ser utilizado no âmbito do patrimônio cultural imaterial para potencializar os efeitos dos instrumentos de salvaguarda. Os atos administrativos deverão ser dirigidos àqueles que atuarem negativamente à continuidade dos bens registrados, prejudicando as práticas ou atingindo bens associados a estes.

\section{INSTRUMENTOS DE SALVAGUARDA DO PATRIMÔNIO CULTURAL IMATERIAL}

No exercício do poder de polícia, a competência material e legislativa sobre o patrimônio cultural reparte-se entre todos os entes políticos da federação, podendo legislar e gerir políticas patrimoniais a União, os Estados e os Municípios, segundo Rodrigues (2008, p. 129).

Relacionadas ao patrimônio cultural imaterial, diferentes políticas culturais vêm sendo adotadas, em nível federal tem-se como os instrumentos mais importantes, o Registro, o Inventário Nacional de Referências Culturais (INRC) e os Planos de Salvaguarda. Diante da efetividade de tais instrumentos é que se busca o poder administrativo sancionador do Estado com o fito de garantir os efeitos destes.

A referência cultural é o ponto de partida desses instrumentos, "falar em referências culturais significa dirigir o olhar para representações que configuram uma 'identidade' da 
região para seus habitantes, e que remetem à paisagem, às edificações e aos objetos, aos 'afazeres' e saberes, às crenças e hábitos” (FONSECA, 2000, p. 11).

Acerca da referência cultural a ser observada, o Manual de Aplicação do Inventário Nacional de Referências Culturais (IPHAN, 2000), exemplifica:

\begin{abstract}
Referências são edificações e são paisagens naturais. São também as artes, os ofícios, as formas de expressão e os modos de fazer. São as festas e os lugares a que a memória e a vida social atribuem sentido diferenciado: são as consideradas mais belas, são as mais lembradas, as mais queridas. São fatos, atividades e objetos que mobilizam a gente mais próxima e que reaproximam os que estão distantes, para que se reviva o sentimento de participar e de pertencer a um grupo, de possuir um lugar. Em suma, referências são objetos, práticas e lugares apropriados pela cultura na construção de sentidos e identidades, são o que popularmente se chama "raiz" de uma cultura (IPHAN, 2000).
\end{abstract}

Os instrumentos de salvaguarda ponderam que os modos de vida das coletividades humanas e o respeito às diferentes configurações culturais e aos valores e referências, devem ser abarcados a partir de seus contextos. A salvaguarda do patrimônio cultural imaterial é baseada na ampla divulgação, valorização, apoio, fomento e garantia das condições de produção e reprodução de bens culturais expressivos da diversidade cultural do Brasil.

A criação de um instrumento legal sobre a salvaguarda do patrimônio imaterial foi proposta em 1997, durante o "Seminário Internacional Patrimônio Imaterial: estratégias e formas de proteção", que resultou na Carta de Fortaleza. O referido documento recomendou a efetivação do inventário dos bens imateriais nacionais e a integração das informações produzidas ao Sistema Nacional de Informações Culturais (SNIC).

Em 1998, o Grupo de Trabalho Patrimônio Imaterial (GTPI), liderado pelo IPHAN, apresentou a proposta técnica do Decreto n $3.551 / 2000$, criando o Registro de bens culturais de natureza imaterial e o Programa Nacional do Patrimônio Imaterial (PNPI).

Para que ocorra a salvaguarda dos bens culturais intangíveis é primordial e necessária a participação das esferas sociais que o cultivam, bem como o seu consentimento. O objetivo da salvaguarda é a realização de ações que valorizem as pessoas e garanta adequadas condições de produção e reprodução do bem cultural em seu contexto.

A seguir, analisar-se-á o INRC, o Registro e o Plano de Salvaguarda como instrumentalização de salvaguarda do patrimônio cultural imaterial, para que no tópico 4 possa ser verificado de que forma o poder de polícia atuaria na efetividade desses instrumentos.

\title{
4.1 Inventário Nacional de Referências Culturais (INRC)
}


Desenvolvido pelo IPHAN como uma metodologia de pesquisa, o INRC busca detalhar as informações sobre os modos da vida social aos quais são atribuídos os sentidos que constituem as referências de identidade para determinado grupo social. Considera-se, além das categorias estabelecidas no Registro, edificações associadas a certos usos, as significações históricas e a imagens urbanas, independentemente de sua qualidade arquitetônica ou artística.

Segundo Fonseca (2009, p. 20), a noção de referência cultural pressupõe a produção de informações e as pesquisas dão os suportes materiais para documentá-las, com a elaboração de dados, de compreensão da ressemantização de bens e das práticas realizadas por determinados grupos sociais, tendo em vista a construção de um sistema referencial da cultura daquele contexto específico.

O INRC não se pauta sobre um bem material ou imaterial específico, mas sobre um lugar, uma região, procurando entender todas as suas referências culturais relevantes. Entretanto, é necessário entender que:

[...] para projetar um inventário não basta adotar os limites e as subdivisões administrativas de uma área geográfica. Os sistemas culturais, e portanto as referências de um grupo social, têm, por assim dizer, uma geografia própria, que dependerá da natureza das relações sociais existentes num determinado espaço físico: a segmentação ou estratificação social corresponderá a clivagens e diferenças culturais, com graus variados de permeabilidade, que deverão ser levadas em consideração na delimitação da área do inventário (IPHAN, 2000, p. 33).

A demarcação da área a ser realizado o INRC ocorre a cargo das referências culturais presentes naquele determinado território. Tais áreas podem ser distinguidas em distintas escalas, podendo corresponder a uma vila, um bairro, uma zona urbana, uma região geográfica culturalmente diferenciada ou um conjunto de segmentos territoriais.

O Inventário, por fim, é um procedimento de investigação que se desenvolve em três níveis de complexidade, inicialmente um levantamento preliminar e mapeamento cultural, em seguida a fase de identificação e descrição das referências culturais relevantes e por fim, a documentação e o desenvolvimento dos estudos técnicos para inserção do banco de dados do INRC.

\subsection{Registro de bens culturais de natureza imaterial}


Previsto pelo Decreto n ${ }^{\circ} 3.551 / 2000$, o Registro de Bens Culturais de Natureza Imaterial é um instrumento legal de preservação, reconhecimento e valorização do patrimônio cultural imaterial do Brasil. O registro não se preocupa com a imutabilidade do bem e a sua possível mutação estética, este deve ser compreendido como:

[...] uma forma de reconhecimento e busca a valorização desses bens. Sendo visto mesmo como um instrumento legal que, resguarda as suas especificidades e alcance. Em síntese: tombam-se objetos, edificações e sítios físicos; registram-se saberes, celebrações, rituais e formas de expressão e os espaços onde essas práticas se desenvolvem (CASTRO; FONSECA, 2008, p. 18).

O registro é tanto a identificação quanto a produção de conhecimento sobre os bens culturais imateriais, aplicado àqueles bens que obedecem às categorias estabelecidas pelo Decreto, quais sejam, as celebrações, os lugares, as formas de expressão e saberes. Assim, as práticas, representações, expressões, lugares, conhecimentos e técnicas que os grupos sociais reconhecem como parte integrante do seu patrimônio cultural podem ser registradas, e ao serem recebem o título de Patrimônio Cultural Imaterial são inscritos em um dos quatro Livros de Registro, de acordo com a categoria correspondente.

O Decreto $\mathrm{n}^{\mathrm{o}} 3.551 / 2000$ estabelece, ainda, o compromisso do Estado em inventariar, documentar, produzir conhecimento e apoiar a dinâmica dessas práticas socioculturais, e favorece um amplo processo de conhecimento, comunicação, expressão de aspirações e reivindicações entre diversos grupos sociais.

Isso significa documentar - pelos meios técnicos adequados - o Patrimônio Cultural Imaterial, revelando o passado e o presente da manifestação e suas diferentes versões, além de tornar as informações amplamente acessíveis ao público, mediante a utilização dos recursos proporcionados pelas novas tecnologias de informação. Os pedidos de registro de bens culturais imateriais devem ser feitos de acordo com os arts. $2^{\circ}$ a $4^{\circ}$ da Resolução No 001/2006.

A instrução de um processo de registro requer pesquisa documental e de campo, mobilização e consenso social sobre motivações e propósitos; argumentação sobre o valor patrimonial da expressão cultural; diagnóstico sobre vulnerabilidade e recomendações para salvaguarda do bem cultural. Trata-se tanto de um processo administrativo, quanto um processo social de mobilização, culminando com a inscrição do bem em um dos livros do Patrimônio Imaterial: Celebrações, Lugares, Saberes, Formas de Expressão.

O registro do bem imaterial é a fase final de um processo jurídico-administrativo e social em torno da salvaguarda do bem cultural em questão, e a cada dez anos é realizada uma reavaliação do registro obtido pelo bem cultural imaterial. 


\title{
4.3 Plano de Salvaguarda
}

O Plano de Salvaguarda do bem cultural de natureza imaterial fundamenta-se em sua continuidade de modo sustentável, atuando para melhoria das condições sociais e materiais de transmissão e reprodução do conhecimento. O conhecimento suscitado no decorrer dos processos de inventário e registro permite identificar as formas mais apropriadas de salvaguardar o bem imaterial, que pode ser desde uma ajuda financeira a detentores de saberes específicos com vistas à sua transmissão, até, a organização comunitária ou a facilitação de acesso a matérias primas.

Vianna (2004, p. 112) afirma que:

\begin{abstract}
A salvaguarda do bem registrado é prevista para ser iniciada no decorrer da primeira década após o Registro, com vistas ao fortalecimento da autonomia dos detentores/produtores do bem cultural na produção, reprodução e gestão de seu patrimônio; e a continuidade do bem cultural no médio e longo prazos. [...] É esperado que possa decorrer algum tempo entre o Registro e o início da elaboração e execução do que se convencionou chamar Plano de Salvaguarda do bem registrado. Não é possível, a priori, definir quanto tempo será necessário para que se apresentem as condições consideradas fundamentais para a implementação do Plano de Salvaguarda, [...]. Entretanto, não obstante a possível demora no alcance destas condições, o IPHAN é responsável pela elaboração e execução de ações de salvaguarda imediatamente após o Registro do bem cultural, conforme a urgência, sempre a partir das recomendações de salvaguarda indicadas no dossiê de Registro e em diálogo com os detentores e eventuais instituições parceiras (VIANNA, 2004, p. 112).
\end{abstract}

Dentre as ações a serem desenvolvidas no Plano de Salvaguarda estão a adoção das medidas administrativas e judiciais de proteção em caso de ameaça ou dano ao bem registrado, seja de qual for a natureza do objeto.

O Plano de Salvaguarda é um instrumento de apoio e fomento de bens intangíveis aos quais são atribuídos sentidos e valores que constituem referências de identidade para os grupos sociais envolvidos, e que são registrados como Patrimônio Cultural Imaterial Brasileiro, conforme o estabelecido no Decreto $\mathrm{n}^{\mathrm{o}} 3.551 / 2000$.

Para a implantação do Plano, o requisito básico é a inscrição de um bem cultural em um dos Livros de Registro do IPHAN. O Registro tem essa função, obrigar a construção desse Plano de Salvaguarda, o que o tombamento não faz. Ao registrar um bem imaterial o Estado fica comprometido a desenvolver um plano de salvaguarda.

O Plano de Salvaguarda deve estabelecer objetivos e metas a serem alcançadas em curto, médio e longo prazo; as estratégias para a obtenção dos resultados esperados, a divisão 
das atribuições dos segmentos signatários de um termo de cooperação, as ratificações e retificações periódicas na condução da política e um monitoramento sistemático para efeito de avaliação. A concretização de experiências nesse sentido - de elaboração de plano de salvaguarda - foi possível inicialmente pela observação de procedimentos adotados e exigidos pela Unesco no tratamento dos bens por ela reconhecidos e que também são registrados, como a Arte Kusiwa e o Samba de Roda (VIANNA, 2004, p. 78).

A implantação de um Plano de Salvaguarda estabelece uma nova relação entre as bases sociais e o Estado, e é com esse instrumento de gestão que espera-se alcançar a autonomia e sustentabilidade da salvaguarda de um bem cultural no médio e longo prazo.

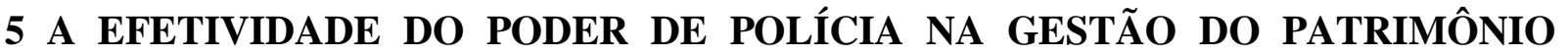 CULTURAL IMATERIAL}

No Brasil, a ideia patrimônio cultural, antes vista como fator de distinção entre as pessoas por suas origens e classes sociais, volta-se para o reconhecimento e a valorização dos traços comuns do povo brasileiro, fundamentalmente diverso, inventivo e fonte dos mais diversos protagonismos.

Diante de tal reconhecimento e valorização está o dever público de preservação do patrimônio cultural, e de normas que ajustem o exercício das liberdades a essa finalidade. $\mathrm{O}$ poder público deve valer-se do dever de polícia ambiental no âmbito cultural, que decorre da afirmação expressa no caput do art. 215 da CR/1988 ao determinar que "o Estado garantirá a todos o pleno exercício dos direitos culturais e acesso às fontes da cultura nacional" (BRASIL, 1988).

Machado (2009) salienta que “ainda que não seja fácil balizar o conteúdo desse dever, pela sua magnitude e profundidade, a afirmação constitucional coloca mais uma obrigação ao Poder Público. Desamparar a cultura é estar omisso e faltoso para com uma das faces de sua missão" (MACHADO, 2009, p. 738).

No momento em que os bens culturais são elevados a bens coletivos relevantes para o direito, faz-se necessário que a Administração Pública quer municipal, estadual ou federal, controle e reprima as atividades potencialmente degradadoras desses bens. O Poder Público tem o poder/dever de intervir na preservação dos bens culturais cumprindo a sua função a fim de promover a ordem jurídica (REISEWITZ, 2004, p. 123).

As atividades do Estado que visam restringir, condicionar e limitar a atuação do particular em nome do interesse público é o poder de polícia, o poder administrativo 
sancionador. Tal poder atua na busca do bem estar social e é alcançado por meio da compatibilização dos interesses públicos e privados.

Apesar dos instrumentos neste estudo analisado (Inventário, Registro e Plano de Salvaguarda) a dinâmica sociocultural do patrimônio cultural imaterial vem exigindo do Estado diversas respostas aos possíveis danos e ameaças que os bens registrados podem sofrer.

A efetividade do poder de polícia na salvaguarda do patrimônio imaterial diverge consideravelmente da aplicabilidade na seara do patrimônio material, cuja atuação consiste na fiscalização e vigilância postos pelo Decreto $n^{0}$ 25/1937. Conforme delineado no início do presente estudo, no campo imaterial pretende-se evitar ao máximo a interferência fiscalizatória do Poder Público.

$\mathrm{Na}$ esfera do intangível, a atuação para o reconhecimento oficial pelo Estado deve pautar-se na livre vontade dos grupos detentores de saberes e práticas imateriais. A partir do momento em que um bem imaterial é individualizado e registrado, questões peculiares vão surgindo envolvendo os bens tutelados, incluindo temáticas de direitos intelectuais, indicações geográficas, propriedade, posse, repartição de acervos, reclamando do Estado uma atuação que não se encaixa nos modos de aplicabilidade do poder de polícia hoje estabelecidos.

No campo material é perceptível a fiscalização ostensiva pelo Estado, com o fim de se verificar se o bem cultural está ou não sendo preservado, transformado, mutilado, destruído na sua materialidade, com aplicação de multas e medidas coercitivas. Já no campo imaterial tal atividade mostra-se inexequível, já que não se verifica a possibilidade de fiscalização, vigilância e qualquer outra ação restritiva, mediante o poder de polícia conferido ao Estado.

Diante do bem registrado é impensável o exercício do poder de polícia para se observar se o frevo está sendo dançado da forma como foi registrado, se o barro das paneleiras de Goiabeiras/ES está na consistência ideal, se o modo de fazer queijo artesanal da região do Serro/MG está correto, porque tais manifestações se alteram e se modificam constante e inevitavelmente. A intervenção ou proteção do Estado não se dá, portanto, no âmbito da prática cultural em si.

É necessário pensar o exercício do poder de polícia do Estado de uma forma que possibilite a continuidade dessas práticas de forma que atenda aos anseios das comunidades interessadas e às exigências do contexto em que estão inseridas.

A resposta do Estado aos danos e ameaças ao patrimônio cultural imaterial deverá sempre estar alinhada àquelas delimitadas nos planos e ações de salvaguarda e ao diálogo com 
as comunidades que os detém, exigindo certo desapego às fórmulas engessadas, prontas e acabadas.

O desafio do Estado na reformulação de seu poder de polícia frente ao patrimônio imaterial se vê ainda diante de situações em que os bens registrados compõem o universo cultural de comunidades tradicionais, como os povos indígenas, cujos hábitos, costumes e visões de mundo muito se diferenciam da lógica que o Poder Público vem trabalhando.

Oliveira (2009) ressalta que "a riqueza das políticas referentes ao patrimônio cultural imaterial situa-se na possibilidade de conhecer respostas diferentes a antigas perguntas, assim como compreender outras possibilidades de ser" (OLIVEIRA, 2009, p. 63).

O poder de polícia no âmbito do patrimônio cultural imaterial será utilizado para potencializar os efeitos do Registro. Os atos de polícia administrativa deverão ser dirigidos àqueles que atuarem negativamente à continuidade dos bens registrados, prejudicando as práticas ou atingindo bens associados a estes.

A título exemplificativo da possibilidade do exercício do poder de polícia no patrimônio cultural imaterial, o art. 70 da Lei $n^{\circ}$ 9.605/1998 dispõe sobre as sanções penais e administrativas aplicadas para a hipótese de crimes e infrações cometidos em face do meio ambiente, nesse conceito abarca o meio ambiente cultural e consequentemente o patrimônio cultural imaterial.

$\mathrm{O}$ art. 72 da Lei $\mathrm{n}^{0}$ 9.605/1998 enumera diversas possibilidades de sanções administrativas que podem ser aplicadas por quem exerce a atividade fiscalizatória, tais como: multa, apreensões, destruição e inutilização de produtos, suspensão de venda e fabricação, ações restritivas de direito, etc. Existem ainda leis especiais de proteção ao meio ambiente cultural e ao patrimônio cultural que preveem outras formas de sanção eficazes na esfera administrativa.

Vieira (2010) salienta que "paira certa timidez dos órgãos e entidades incumbidos da fiscalização do patrimônio cultural, padecendo as instituições de verdadeira omissão no exercício das competências e atribuições que possuem ao seu encargo" (VIEIRA, 2010, p. 89).

Nesse sentido, conclui-se que por se tratar de um patrimônio cultural relativamente novo o que tem se verificado é certa dificuldade de se conjugar, os poucos instrumentos que se compatibilizam com o bem intangível. É necessário conclamar a aplicação de tais instrumentos existentes na ordem jurídica para a efetiva proteção do patrimônio cultural imaterial. 


\section{CONSIDERAÇÕES FINAIS}

Demonstrou-se neste artigo a importância do patrimônio cultural imaterial como forma de referenciar as diversas culturas que compõe o Brasil e no intuito de sua preservação e salvaguarda, qual a sua relação com o poder de polícia do Estado.

O patrimônio cultural vincula-se a ideia de memória coletiva, dos processos de construção das comunidades e dos valores que estas vão atribuindo a determinado bem, o individualizando dos demais e carecendo de proteção jurídico-estatal.

No Brasil, a partir da década de 1920 as discussões acerca da proteção do patrimônio artístico e histórico tomaram forma, e liderados pelo Movimento Modernista inauguram os debates propondo a valorização e salvaguarda do patrimônio cultural nacional com fortes críticas aos modelos até então propostos.

Em 1937 com a edição do Decreto-Lei nº 25/37, em vigor até hoje, o patrimônio artístico e histórico brasileiro passou a ter legislação específica, instituindo o tombamento como forma de proteção dos bens físicos, ou seja, o patrimônio cultural material.

A proteção constitucional do patrimônio cultural imaterial surge com a CR/1988 e é efetivada legalmente pelo Decreto $n^{\circ} 3.551 / 2000$. O patrimônio cultural imaterial compreende os saberes, ofícios e modos de fazer, celebrações, formas de expressão cênicas, musicais ou lúdicas e os lugares que dizem respeito às práticas e modos de vida dos diferentes povos que compõem o Brasil.

Por se tratar de um instituto jurídico ainda recente e pouco analisado na esfera jurídica, muitos questionamentos ainda vêm sendo feitos acerca de sua aplicabilidade e a forma como o Estado pode atuar com seu poder de polícia, a fim de preservar o bem imaterial registrado.

O poder de polícia, entendido como a necessidade de ordenação do convívio coletivo exercido pelo poder público, tem o dever de impor limites ao exercício de direitos e liberdades do particular. E nesse fito, tem-se a polícia ambiental responsável por limitar e disciplinar o patrimônio cultural, visto que esse se enquadra no conceito de meio ambiente cultural.

A fim de realizar um estudo crítico sobre os bens de natureza imaterial protegidos pelo poder público, buscou-se analisar a possibilidade de atuação do poder administrativo sancionador sobre esses bens, apresentando os instrumentos para sua salvaguarda e o poder de polícia como potencializador de sua proteção.

Verificou-se que os instrumentos utilizados na proteção do patrimônio imaterial (inventário, registro e plano de salvaguarda) servem como norte para a atuação do Estado em 
sua preservação, mas não podem ser fim, faz-se necessária a conjugação entre tais instrumentos e a atuação do Estado com seu poder de polícia, que ainda se mostra tímida, seja pela novidade do tema ou mesmo pela ineficiência dos órgãos que detêm tal responsabilidade.

Por fim, verificou-se a necessidade de uma maior interação do Direito no campo no patrimônio cultural, especialmente o imaterial, que até então encontra-se muito discutido nos estudos da Antropologia e da Sociologia, mas carecendo de uma visão jurídica acerca de sua salvaguarda.

\section{REFERÊNCIAS}

BRASIL. Constituição da República Federativa do Brasil de 1988. Diário Oficial, Brasília, 05 out. 1988. Disponível em: 〈http://www.planalto.gov.br>. Acesso em: 20 jun. 2015.

BRASIL. Decreto-Lei n ${ }^{\circ}$ 25, de 30 nov. 1937. Organiza a proteção do Patrimônio Histórico e Artístico Nacional. Diário Oficial, Brasília, 06 dez. 1937. Disponível em: <http://www.planalto.gov.br>. Acesso em: 20 jun. 2015.

BRASIL. Decreto $n^{\circ}$ 3.551, de 04 ago. 2000. Institui o Registro de Bens Culturais de natureza Imaterial que constituem o patrimônio cultural brasileiro, cria o Programa Nacional do Patrimônio Imaterial e dá outras providências. Diário Oficial, Brasília, 04 ago. 2000. Disponível em: <http://www.planalto.gov.br>. Acesso em: 20 jun. 2015.

BRASIL. Lei $\mathrm{n}^{\circ}$ 9.605, de 12 fev. 1998. Dispõe sobre as sanções penais e administrativas derivadas de condutas e atividades lesivas ao meio ambiente. Diário Oficial, Brasília, 13 fev. 1998. Disponível em: 〈http://www.planalto.gov.br〉. Acesso em: 20 jun. 2015.

BRASIL. Lei n ${ }^{\circ}$ 5. 172, de 25 de Outubro de 1966. Dispõe sobre o Sistema Tributário Nacional e Institui Normas Gerais de Direito Tributário Aplicáveis à União, Estados e Municípios. Diário Oficial da União. Brasília, 25 de outubro de 1966.

CASTRO, Maria Laura Viveiros de; FONSECA, Maria Cecília Londres. Patrimônio imaterial no Brasil. Brasília: UNESCO, Educarte, 2008. 198p.

CHOAY, Françoise. Alegoria do Patrimônio. São Paulo: UNESP, 2001. 304p.

CURY, Isabelle. Carta de Fortaleza. In: CURY, Isabelle (Org.). Cartas patrimoniais. 2. ed. Rio de Janeiro: IPHAN, 2000. p. 363-365

DI PIETRO, Maria Sylvia Zanella. Direito Administrativo. 17. ed. São Paulo: Atlas, 2004. 800p.

FERREIRA, Aurélio Buarque de Holanda. Aurélio século XXI: o dicionário da Língua Portuguesa. 3. ed. Rio de Janeiro: Nova Fronteira, 1999. 2.128p. 
FONSECA, Maria Cecília Londres. O patrimônio em processo: trajetória da política federal de preservação no Brasil. 3. ed. Rio de Janeiro: UFRJ, 2009. 296p.

FONSECA, Maria Cecília Londres. Referências culturais: base para novas políticas de patrimônio. In: Manual de aplicação do INRC. Brasília: MinC/IPHAN/Departamento de Documentação e Identificação, 2000. p. 11-21.

IPHAN. Manual de aplicação do Inventário Nacional de Referências Culturais. Brasília: IPHAN, 2000. 156p.

MACHADO, Paulo Affonso Leme. Direito ambiental brasileiro. 11. ed. São Paulo: Saraiva, 2009. 1.344p.

MEDAUAR, Odete. Direito administrativo moderno. 3. ed. São Paulo: Revista dos Tribunais, 1999.1.635p.

MEIRELLES, Hely Lopes. Direito municipal brasileiro. 12. ed. São Paulo: Malheiros, 2001. 870p.

MELlO, Celso Antônio Bandeira de. Curso de Direito Administrativo. 21. ed., São Paulo: Malheiros, 2006. 1.150p.

MINAS GERAIS. Decreto n. 45.850, de 28 de dezembro de 2011. Estatuto do Instituto Estadual de Patrimônio Histórico e Artístico de Minas Gerais - IEPHA-MG. Diário Oficial, Belo Horizonte, 29 dez. 2011. p. 28.

MIRANDA, Marcos Paulo de Souza. Tutela do patrimônio cultural brasileiro: doutrina, jurisprudência e legislação. Belo Horizonte: Del Rey, 2006. 480p.

MORENO, Beatriz Gonzáles. Estado de Cultura, derechos culturales y libertad religiosa. Madrid: Civitas, 2003. 359p.

OLIVEIRA, David Barbosa de. A solidariedade intergeracional do patrimônio cultural imaterial. Direitos Culturais, Santo Ângelo, v. 4, nº 7, jul./dez. 2009. p. 55-68.

PIRES, Maria Coeli Simões. Da proteção ao patrimônio cultural: o tombamento como principal instituto. Belo Horizonte: Del Rey, 1994. 413p.

RABELLO, Sonia. O Estado na preservação dos bens culturais: o tombamento. Rio de Janeiro: IPHAN, 2009. 156p.

REISEWITZ, Lúcia. Direito Ambiental e patrimônio cultural: direito à preservação da memória, ação e identidade do povo brasileiro. São Paulo: Juarez de Oliveira, 2004. 179p.

RODRIGUES, Francisco Luciano Lima. Patrimônio Cultural: a propriedade dos bens culturais no Estado Democrático de Direito. Fortaleza: Universidade de Fortaleza, 2008. 271.p. 
SANTILLI, Juliana. Patrimônio Imaterial e direitos intelectuais coletivos. In: CUNHA, Manuel Carneiro da (Orgs.). Revista do Patrimônio Histórico e Artístico Nacional no 32/2005. Patrimônio Imaterial e Biodiversidade. Brasília: IPHAN, 2005. p. 44-61.

SILVA, José Afonso da. Direito Ambiental Constitucional. 5. ed. São Paulo: Malheiros, 2004. 374p.

SOUZA FILHO, Carlos Frederico Marés de. Proteção Jurídica dos bens culturais. São Paulo: Revista dos Tribunais, 2005. 178p.

UNESCO, 2003, Convenção para a Salvaguarda do Patrimônio Cultural Imaterial, Decreto n. ${ }^{\circ}$ 28/2008 de 26 de Março, Diário da República n. ${ }^{\circ}$ 60, 1685-1704. Disponível em: <http://portal.UNESCO.org>. Acesso em: 20 jun. 2015.

VIANNA, Letícia C. R. Legislação e Preservação do Patrimônio Imaterial: perspectivas, experiências e desafios para a salvaguarda da cultura popular. Textos Escolhidos de Cultura e Artes Populares, Brasília, v. 1, nº 1, , 2004. p. 75-83.

VIEIRA, Jamerson. Patrimônio Cultural: um estudo sobre a tutela administrativa das paisagens culturais no contexto dos instrumentos de proteção previstos no ordenamento jurídico brasileiro. 165 f. Dissertação (Mestrado), Pontifícia Universidade Católica de Minas Gerais, Programa de Pós-Graduação em Direito, Belo Horizonte, 2010. 